\title{
Effectiveness of a verbal reinforcer subsequent to satiation in preschool children
}

\author{
HAROLD COOK, Teachers College, \\ Columbia University, New York, N.Y. \\ 10027
}

Satiation implies a loss of meaning or reduction in the effectiveness of a stimulus following its continued repetition. It was hypothesized that satiation should reduce the effectiveness of a verbal reinforcer. Ss were assigned randomly to treatment groups in $a 2$ by 2 by 5 factorial design. During a baseline phase, $S s$ in a free-operant task dropped marbles into either of two holes, and a low preference side was determined for each $S$. Each $S$ then continually repeated aloud "good" (a positive reinforcer) or "plant" (a neutral word) for 20,15, 10, 5, or 0 sec. In the conditioning phase, each $S$ was verbally reinforced by E ("good" or "plant") for each marble-drop response made to his low-preference side. Analysis of variance showed a significant main effect for duration of repetition $(p<.01)$.

Verbal satiation or loss in meaning of a word following continued repetition or prolonged inspection has been demonstrated by a number of investigators who have related the effects of semantic satiation to diverse areas (see Cook \& Vachon, 1968; Das, 1966; Jakobovits, 1965; Jakobovits \& Lambert, 1962). Gewirtz \& Baer (1958) have demonstrated that social reinforcers appear responsive to deprivation and satiation operations of a similar order as those controlling for the effectiveness of reinforcers of primary drives. Recently Cook (1968) and Gewirtz (1969) have systematically explored the effect of verbal satiation on verbal reinforcers.

Amster (1964) and Zajonc (1968) review the relevant literature and present some of the inconclusive results and controversy inherent in the field of semantic satiation. The present study attempts to provide some additional data by investigating (1) the verbal satiation process in preschool children, (2) the application of a technique to measure the effect of satiation of a verbal reinforcer upon a later verbally reinforced operant task, and (3) the degree to which reinforcer effectiveness is altered by varying amounts of continued repetition (semantic satiation) of a positive verbal reinforcer.

Specifically, the continuous repetition of the word "good" should diminish its reinforcing effectiveness in the performance of an operant task, and the longer the duration of continuous repetition, the greater the decrement. METHOD

The Ss were 64 preschool children from four nursery schools. Their mean age was 48 months, with a range of 40 to 60 months. Four Ss were dropped from the study because they did not complete all phases or they did not make at least one response to their low preference side during the conditioning.

The Ss were randomly assigned to groups in a 2 by 2 by 5 fixed effect, complete factorial design. The factors were: (1) the word used as the satiator, either "good" or "plant" (a neutral control word), (2) the word used as the reinforcer, either "good" or "plant," and (3) the duration of repetition, $0,5,10,15$, or 20 sec. The dependent measure was S's increase or decrease in percent of responses from baseline to conditioning on his low preference side, the side least preferred by $\mathrm{S}$ during his baseline period.

The apparatus consisted of a specially built "marble game." (See Cook, 1968, for details of the apparatus). The marble, when dropped through one of two holes on the top surface of the marble game, rolled down a contoured metal runway that funneled the marble out of a clown's mouth into a small plastic container. Counters activated by separate microswitches, located in each of the metal runways, recorded the number of marble drops made to each side when the marble passed over them.

\section{PROCEDURE}

All Ss were run individually. The procedure can be conveniently broken down into three phases: (1) baseline, (2) repetition, and (3) conditioning.

\section{Baseline}

E engaged $S$ in friendly conversation and seated $S$ at a table on which the apparatus was placed. E sat opposite $S$ and said: "Do you like to play with marbles? Fine. We are going to play this ( $\mathrm{E}$ pointed to the apparatus) marble game. It's very easy. Do you see the two holes on the top of the box? (E pointed to the holes.) Fine. You're to put this marble in one of the two holes, and wait until it drops out of the clown's mouth into the tray. Pick up the marble and keep putting it in one of the holes. Don't stop until I tell you to stop. Do you understand how to play the game? Now, let's see how many times you can put the marble in one of the two holes. O.K.
Begin." $S$ played the marble game for $3 \mathrm{~min}$. If $\mathrm{S}$ stopped putting the marble in the holes before the 3-min period ended, E said: "You are to keep putting the marble in one of the two holes." After $3 \mathrm{~min}, \mathrm{E}$ said: "Let's stop for now. You're doing fine." $E$ recorded the number of responses $S$ made to each side and reset the counters at zero. E was an attentive but nonreinforcing observer of S's performance.

\section{Repetition}

All Ss except the no-satiation Ss (they rested for approximately $15 \mathrm{sec}$ ) received the following instruction: "Now we are going to play another game. It's a word game. I will say a word and then I want you to say the word and keep on saying the word over and over again until I tell you to stop. For example, if I say the word fun, you would say fun, fun, fun, fun, without stopping. Do you understand? O.K., now you say 'good/plant' (depending on which group $S$ was in) until I tell you to stop." $E$ stopped $S$ at the end of the designated interval appropriate for S's group.

All Ss then underwent conditioning and were instructed: "That's fine. Let's go back to playing our marble game. Remember, put the marble in one of the two holes. Keep putting the marble in the holes until I tell you to stop. O.K. Begin." E reinforced $S$ by saying "good/plant" when $S$ dropped the marble into the "correct" hole, defined as that preferred least during the 3-min baseline phase. After $3 \mathrm{~min}, \mathrm{E}$ stopped and thanked each $S$ and gave each $S$ a trinket.

\section{RESULTS}

Response frequencies obtained during the baseline period were examined to determine high and low side preferences for each S. Of the $60 \mathrm{Ss}, 23$ displayed leftand 27 right-side preferences. Percent transformations were performed on both the baseline and the conditioning high and low preference response frequencies. The dependent variable was the increase in percent of responses from the baseline to the conditioning task on the low preference side. This low preference side, right or left, was the side least preferred by each $S$ during the initial 3 -min baseline task.

A four-way analysis of variance fixed-effects model with one repeated measures variable was performed on the data. The variables in the fully crossed design were: (1) the word used as the satiator ("good" or "plant"), (2) the word used as the reinforcer in the conditioning phase ("good" or "plant"), (3) the duration of repetition (seconds of repetition), $0,5,10,15$, or $20 \mathrm{sec}$, and (4) the baseline percent of responses made 
Fig. 1. Interaction of percent change by satiator and reinforcer across duration of repetition.

to the initial low preference side and the conditioning percent responses made to the initial low preference side.

The results of this analysis indicate a significant main effect for the duration of repetition $(F=4.36, \mathrm{df}=4 / 40, \mathrm{p}<.01)$ and for the increase in percent of responses from baseline to conditioning $(F=24.34$, $\mathrm{df}=1 / 40, \mathrm{p}<.001$ ). As the duration (in seconds) of repetition increased, the average percent of responses tended to decrease. Also, the 0-sec repetition (no satiation) condition yielded an average increase of $25.3 \%$ from baseline to conditioning, whereas the $20-\mathrm{sec}$ condition yielded an $8.8 \%$ average increase. Means for the main effect for overall change indicated a net change of $16.1 \%$, the mean baseline of 33.6 changing to a mean conditioning of 49.7. There were no significant differences across groups in percent baseline low preference side responses, indicating initial comparability between the groups.

When the various trend components of the duration-of-repetition (in number of seconds) variable were examined, several interesting relationships appeared. The overall effect of the duration of repetition for the five levels on the average percent shift within each level, was linear $(F=4.14, p<.05)$. The trend analysis on the interaction of the Reinforcers by Duration-of-Repetition variable was linear in form $(F=8.12, p<.01)$ and showed a dramatic shift across duration of repetition for "good" as the reinforcer, and a negligible shift for "plant" as the reinforcer. The interaction of Satiator by Duration of Repetition displays two differential cubic (S-shaped) functions. Both response shift curves for groups receiving "good" as a satiator and for groups receiving "plant" as a satiator assume " $S$ " shapes across duration of repetition. However, these "S"-shaped or cubic functions are significantly nonparallel $(F=6.14, \mathrm{df}=1 / 40, \mathrm{p}<.05)$. This is true particularly with respect to the 5,15 , and $20 \mathrm{sec}$ of repetition conditions. Evaluation of the three-way interaction (Word Used as Satiator by Word Used as Reinforcer by Duration of Repetition) revealed the existence of a dominant cubic interactive trend $(F=7.80, p<.01)$ over the linear interactive trend $(F=4.13$, $\mathrm{p}<.05$ ) for response shift. See Fig. 1.

\section{DISCUSSION}

The rasults of the present experiment, in accord with the hypothesis, indicate that the effectiveness of a verbal reinforcer can be altered by continued repetition of that reinforcer. That the continued repetition

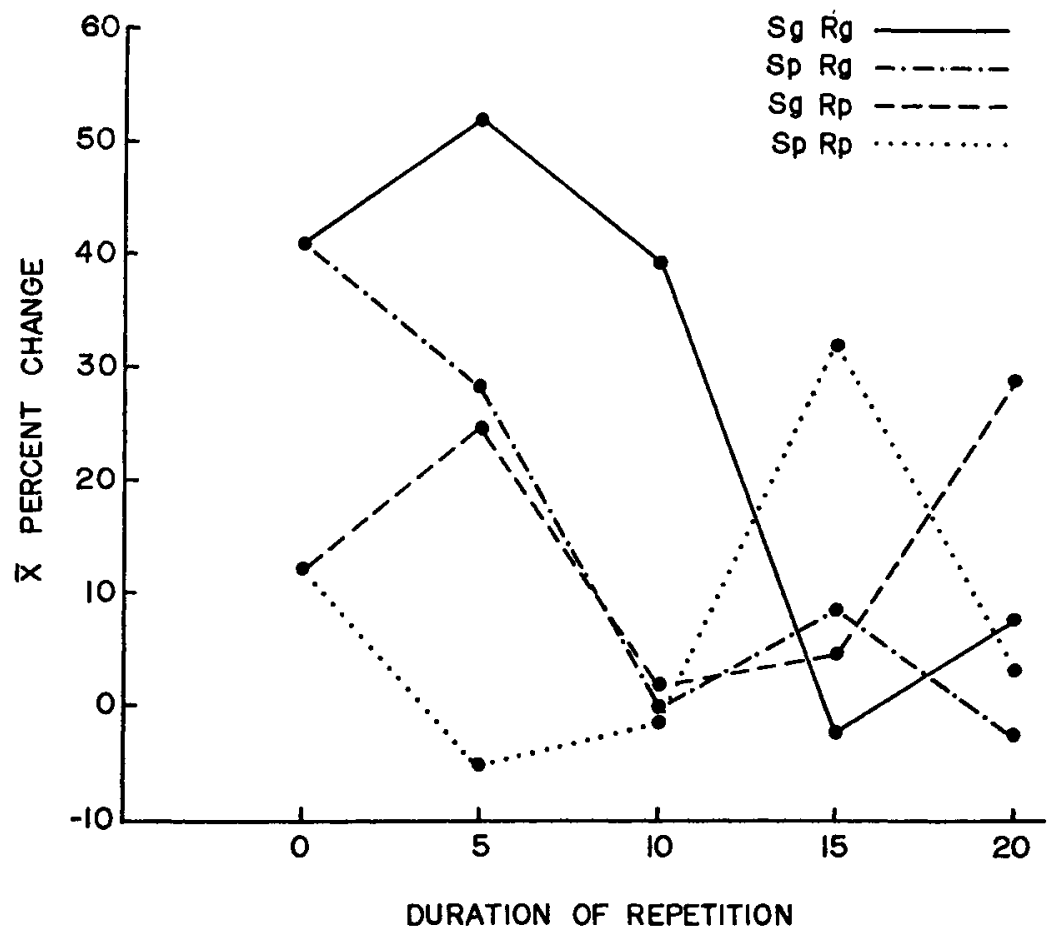

of a word decreases its reinforcing properties is supported by the significant main effect obtained for duration of repetition and the significant trend analysis of linearity on percent shift across the durations of repetition. These findings appear in general agreement with Cook (1968) and Gewirtz (1969) and show that varied amounts of repetition have differential effects on reinforcer effectiveness.

The significant three-way interaction of the Word Used as the Satiator by Word Used as the Reinforcer by Duration of Repetition suggests that the differential effects were primarily concentrated in groups having the same word for both satiator and reinforcer. In particular, the performance shift curve for groups that had "good" as the satiator and reinforcer $\left(\mathrm{S}_{\mathrm{g}} \mathrm{R}_{\mathrm{g}}\right)$ displayed a maximum shift of $53 \%$ at $5 \mathrm{sec}$ of repetition, implying maximum reinforcer effectiveness (a prompting or priming effect) and a minimum satiation effect. A minimum shift of $-2 \%$, implying maximum satiation, minimum reinforcer effectiveness, occurred at $15 \mathrm{sec}$ of repetition. The $20-\mathrm{sec}$ group also demonstrated a decrease in the effectiveness of the reinforcer, but not to the same degree as the 15-sec group. These results appear to be in agreement with Fillenbaum (1963, p. 268) "... two or three presentations of a word ( 4 seconds of repetition) might alert a person to some features of its meaning even if continual elicitation eventually were to lead to a change or loss of meaning."
Groups for which "plant" (a word assumed to have neutral reinforcing properties) was the satiator and the reinforcer $\left(S_{p} R_{p}\right)$ displayed a maximum satiation and minimum reinforcer effectiveness at the 5-sec level with a shift of $-6 \%$, signifying an extreme decrease in reinforcer effectiveness. Minimum satiation and maximum reinforcer effectiveness occurred at the 15-sec level, shifting $34 \%$. This sharp increase for the $S_{p} R_{p}$ group resulted in the greatest amount of reinforcer effectiveness. In contrast, the $S_{g} R_{g}$ group showed the least reinforcer effectiveness at $15 \mathrm{sec}$ of repetition. At $20 \mathrm{sec}$, the $S_{p} R_{p}$ group demonstrated a decrease in reinforcer effectiveness.

The differences between the results obtained for the two words ("plant" and "good"), when they are both used as satiator and reinforcer, appear to be complex. The fact that meaningful words are learned more readily than less meaningful words hardly needs documentation. It should follow that meaningful words ("good") retain their meaning more readily than meaningless words ("plant"). The word "good," by its nature of having strong positive reinforcing properties, could be considered a "more meaningful" word than "plant." "Good," as a positive reinforcer, therefore, should show more inhibition of these meaningful reinforcing properties after longer durations of repetition. Since satiation treatment to a particular word "lowers the meaning" of that word, "good" will lose some degree of intensity of its positive 
meaning after being repeated continuously. Whereas "plant," assumed to have a negligible amount of positive meaning in contrast to "good," will lose its intensity of positive meaning more readily and show less persistence of negligible positive meaning. Perhaps the satiation treatment for "plant" and "good" was contaminated by the differential persistence of the positive meaning of the two words.

The unexpected finding that reinforcer effectiveness is reduced even when the satiated word is different from the word used as the reinforcer, i.e., repetition of the word "plant" appeared to reduce the effectiveness of "good" as a reinforcer, may imply that satiation involves a general nonspecific factor described behaviorally as boredom, a loss of attention, or, more specifically, by habituation of the orienting response (Das, 1966).

The relatively consistent differences obtained between the two words and between the varied durations of repetition (Cook, 1968) pose problems that are unanswerable within the existing theoretical framework employed to explain the satiation effect. The attempts to do so were primarily suggestive. Yet, the results indicate that the satiation effect (1) occurs in very young children, (2) is dependent on the duration of the continued repetition, (3) alters reinforcer's effectiveness, and
(4) may be indexed and assessed by the enhancement or decrement of the effectiveness of a verbal reinforcer in the performance of an operant task.

\section{REFERENCES}

AMSTER, H. Semantic satiation and generation: Learning? Adaptation? Psychological Bulletin, $1964,62,273-286$.

$\mathrm{COOK}, \mathrm{H}$. Verbal satiation of a positive and negative reinforcer in children. Journal of Verbal Learning \& Verbal Behavior, 1968, 7, 1082-1087.

COOK, H., \& VACHON. J. Satiation of a verbal cue in problem solving in French speaking children. Psychonomic Science, 1968, 11, 208.

DAS, J. P. Relation between semantic satiation and verbal conditioning. British Joumal of Psychology, 1966, 57, 87-91.

FILLENBAUM, S. Verbal satiation and changes in meaning related terms. Journal of Verbal Learning \& Verbal Behavior, 1963, 2, 263-271.

GEWIRTZ, J. L. Potency of a social reinforcer as a function of satiation and recovery. Developmental Psychology, 1969, 1, 1-13.

GEWIRTZ, J. L., \& BAER, D. M. Deprivation and satiation of social reinforcers as drive conditions. Journal of Abnormal Social Psychology, 1958, 57, 165-172.

JAKOBOVITS, L. A. Semantic satiation in concept formation. Psychological Reports, $1965,17,113-114$.

JAKOBOVITS, L. A., \& LAMBERT, W. E. Mediated satiation in verbal transfer. Joumal of Experimental Psychology, 1962, 64, 346-351.

ZAJONC, R. B. Attitudinal effects of mere exposure. Journal of Personality \& Social Psychology Monograph Supplement, 1968, 9, (Part 2).

\section{Interitem interval and total time in}

serial learning ${ }^{1}$

\begin{abstract}
JAMES M. POLT, Temple Buell College, Denver, Colo. 80220, and KAREN GRIENEEKS, University of Maine, Orono, Maine 04473
\end{abstract}

Eleven groups of 12 Ss each were required to learn a list of eight $C V C$ trigrams presented on a memory drum to a criterion of one perfect trial. The effect of dividing presentation rates of $2,4,8$, and $16 \mathrm{sec}$ into various periods of stimulus duration and interitem (blank) intervals was related to total time to criterion. It was found that the longer presentation rates did not facilitate learning the serial list and that there was a significant drop in efficiency in learning the list at the 16-sec rate. When the stimulus duration was
The second variable dealt with in this study was the rate of item presentation as it affects learning. A number of studies have supported the total-time hypothesis with a wide range of presentation times in paired-association learning (PAL), particularly where the stimulus duration is held constant (Bugelski, 1962, used presentation times that ranged from 6 to $19 \mathrm{sec})$. Cooper \& Pantle (1967), however, noted that while the total-time hypothesis has been supported in SL, the limited range of presentation rates used, typically $2 \mathrm{sec}$ and $4 \mathrm{sec}$, has produced "less impressive" evidence in support of the total-time hypothesis. One study which used a wider range of presentation rates was Fischer (1966). Using times of $2,4,6,8$, and $16 \mathrm{sec}$, her data supported the total-time hypothesis, though learning tended to take longer with the 16 -sec presentation rate.

\section{METHOD}

The apparatus used in this study was a Lafayette memory drum with a variable shutter. A list of eight CVC nonsense syllables selected from Archer (1960), with association values ranging from $48 \%$ to $50 \%$, was presented to 11 groups of $12 \mathrm{Ss}$ each. All Ss were freshman and sophomore women enrolled in introductory psychology courses and were randomly assigned to one of the 11 groups.

Four rates of presentation were used: 2 , 4,8 , and $16 \mathrm{sec}$. Within each presentation rate, the item was present in the window for: (1) the entire period (Groups 2-2, 4-4, $8-8$, and 16-16, with no interitem interval); (2) one-half the period (Groups 2-1, 4-2, $8-4$, and $16-8$, with interitem intervals of 1 , 2,4 , and $8 \mathrm{sec}$, respectively); (3) $1 \mathrm{sec}$ (Groups 2-1, 4-1, 8-1, and 16-1, with interitem intervals of $1,3,7$, and $15 \mathrm{sec}$, respectively).

The Ss were instructed that the syllables would always appear in the same order, that a blank space would occur between syllables (where appropriate), that they were to spell out their anticipations, and that the experiment would continue until they could anticipate each item correctly on a single presentation (i.e., criterion for learning was one perfect trial). An asterisk was used as a cue at the beginning of the list, and all Ss were presented the syllables in the same order.

\section{RESULTS}

The mean total times for learning the list by the various groups are shown in Table 1 . The conventional procedure of presenting serial anticipation lists, with no interval between items, was represented by Groups $2-2,4-4,8-8$, and 16-16 and showed a general decrease in efficiency of time spent learning the list as the presentation rate increased. The exception is a reversal between Groups $4-4$ and $8-8$. The only 